\title{
The role of management capacity for the SD of small and medium enterprises in Vietnam
}

\author{
Hung Do Hai \\ Faculty of Business Management \\ Hanoi University of Industry \\ dohaihung@haui.edu.vn
}

\author{
Cuong Nguyen Manh \\ Faculty of Business Management \\ Hanoi University of Industry \\ nguyencuonghaui@gmail.com
}

\begin{abstract}
In the context of increasingly extensive international integration, the 4th industrial revolution is expanding to all areas of production. That is increasingly expanding and putting into practice, the sustainable development (SD) of enterprises of small and medium enterprises (SMEs) depends greatly on the management capacity of the team of administrators in the enterprise. The study selected research scope in Vietnam, to survey of 316 SMEs of different business sectors and territories. The study results showed that, the role of management capacity for the SD (SD) of SMEs in Vietnam very important, the influence level of management capacity has a greater than other factors as: State and local support policies, innovation consciousness, corporate social responsibility, finance and human resources.
\end{abstract}

Index Terms-Management capacity; SD; Small and medium enterprises.

\section{INTRODUCTION}

$\mathrm{E}$ NTERPRISES'S SD not only meeting the needs of businesses and stakeholders in the present but also protect and maintain the growth of available human resources and natural resources in the future (VCCI,2020). SD needs to focus on the relationship between industry capacity, technology, institutional and market development capacity. Their interaction to realize SD of enterprises. In order to maintain SD in the SMEs, it is necessary to improve the management capacity of managers from senior to grassroots level in the context of deepening international integration.

Based on the data of Vietnam Chamber of Commerce and Industry (VCCI), the whole country has 758,610 operating enterprises, of which small and medium enterprises (SMEs) account for over 95\% [1]. One of the limitations of SMEs is low labor productivity, mainly manual labor. It usually only sell a number of products that are suitable for the qualifications, experience and financial capabilities of the business owner; Financial resources are limited and the ability to access credit sources from organizations is still low; In addition, they are usually employ few workers and the workers are mainly indigenous workers [2]. SMEs in Vietnam are always in the vicious circle of low competitiveness due to lack of capital, but it is difficult to access credit due to lack of collateral so investment in innovation is slowly; Outdated technology is associated with poor management capacity, so costs are high, competitiveness is low, and there is little opportunity to access production orders with high added value [3]. Therefore, the capacity of the managers is an indispensable factor to lead the organizaion [4].

Based on the current situation of SMEs in Vietnam, it is necessary to evaluate the role of management capacity for the SD of SMEs in Vietnam. The objective of the study is to identify and measure the influence of the management capacity with the other factors for the SD of SMEs in Vietnam.

\section{Literature Review and Theoretical Framework}

\section{A. Literature rReview}

Management capacity is usually assessed through the qualifications of the management staff from senior to grassroots level in the enterprise's apparatus. The senior managers in SMEs have limited knowledge of management and less interested in building long-term development strategies as well as building structure of enterprises. The management process of enterprises, especially the finance management have not been implemented by SMEs owner and low quality. So that, their enterprises can not manage work including financial status and business performance. This greatly affects the production and business activities of SMEs in developing countries. Achieving organizational goals through knowledge and skills of managers requires them to have good competence, certain knowledge of the legal system, education, tax in business, production line, technology [5].

In management capacity field, management skills also are very important issue. This skill includes skills from planning, organizing and evaluating business operations. Planning is the process of setting and setting goals. Difficulties, obstacles, changes in the business environment and preparation of contingency plans are issues that managers need to anticipate. [6]. These skills will help managers have a good relationship with colleagues, creating motivation to work for those around them. This allows activities in the organization to take place easily and quickly [7]. According to the research of Le Ngoc Nuong (2018) [8], The results show that most countries pay special attention to the development of SMEs in order to maximize resources and support large enterprises. This issue will help businesses increase their competitiveness in production and business activities. To create that result, the element of management capacity is very important.

Luminita. P (2020) with the research about the role of managerial, the results of the study show that, an entrepreneur will only be limited to interacting with certain people compatible with their communication style when they do not have effective communication skills thus limiting their ability to communicate effectively with the colleagues, ability 
to communicate effectively with the colleagues, ability to communicate one's vision and goals further. Therefore, developing management skills is much more complex than developing other skills. It is based on diverse knowledge and skills of communication between different people in an organization [9].

It can be seen that studies have clarified the role of management capacity for SD of SMEs in Vietnam. At present, this issue has not been specifically considered and evaluated of studies in Vietnam. Therefore, the objecties of the study is necessary to evaluate the role of management capacity in practice compared with other factors affecting SD of SMEs in Vietnam.

\section{B. Theoretical framework}

Management capacity is a combination of knowledge, skills and qualities of an administrator to complete the management functions in an enterprise, including: planning, organizing, leading and controlling [10]. Management capacity is the knowledge, skills and capabilities of business owners that can help SMEs operate more effectively. Management skills of business owners are essential for the existence and sustainable growth of enterprises. If the business owner lacks management skills, it is a big barrier to the development and the cause for production and business activities being interrupted.

$\mathrm{SD}$ of enterprises need to focus on the relationship between industry capacity, technology, institutional and market development capacity. Their interaction to realize SD of enterprises. Can be realize the SD of enterprises, we must pay attention to the selection and orientation of the industry, technological innovation, institutional reform and capacity building for market development [11]. He shown that: SD of enterprises is to associate between external influences and internal constraints, the control process determines the sustainability, allowing the basic organization sustainable and effective methods.

\section{METHODOLOGY}

The business environment is considered a significant factor affecting the SD of SMEs, including factors outside the enterprise, orientation and direct influence on management activities in the enterprise. The government supporting plays a very important role in creating an attractive political and investment environment not only for SMEs but also the business system [8].

Hypothesis 1: The Government support policy factor has a positive influence for the SD of SMEs in Vietnam.

\section{A. Research model}

Most of the owners of SMEs have limited organizational and management knowledge which are less interested in building long-term development strategies, as well as building an appropriate organizational structure for the business. This greatly affects the SD process of the enterprises [12]. Hypothesis H2: The management capacity factor has a positively influence for the SD of SMEs in Vietnam.
The manufacturing technology of SMEs has a great influence on productivity, product quality, production efficiency, environmental pollution levels during production and discharge into the environment. There is affecting the development process of enterprises in the long term [8].

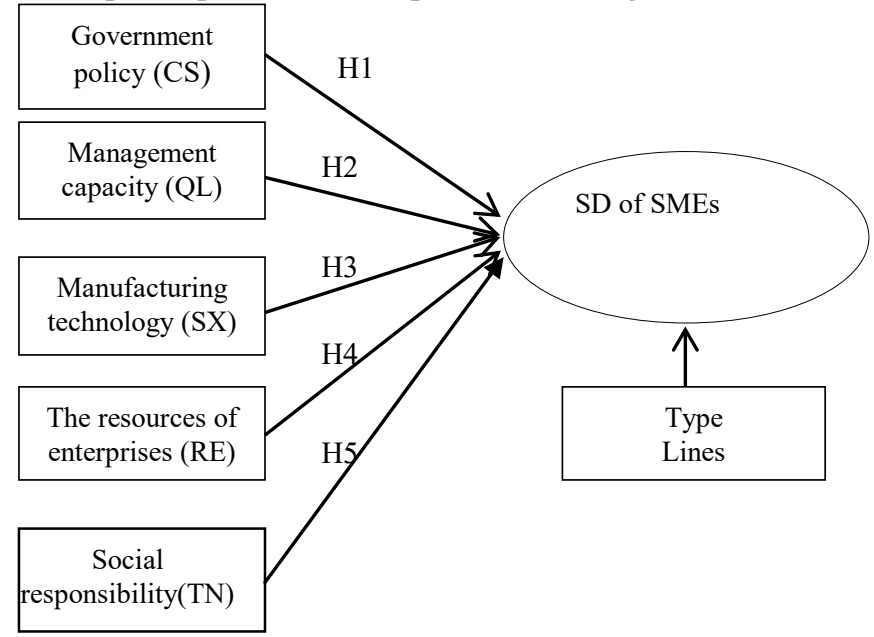

Fig. 1 Research model

Hypothesis 3: The manufacturing technology factor has a positive influence for the SD of SMEs in Vietnam.

Labor force and quality of labor force is a consideration criterion to evaluate the SD of SMEs. Besides the human resource factor, the difficulty in accessing external capital is the main obstacle to the development of SMEs, it is one of the causes of business failure [13].

Hypothesis H4: The resources of enterprises factor have a positive influence for the SD of SMEs in Vietnam.

Businesses that perform well on social responsibility will gain significant benefits, such as: increase the brand value of the business and expand the market to increase revenue, reduce costs, and increase labor productivity. Therefore, the implementation of social responsibility is increasingly recognized by businesses and considered as an indispensable requirement towards the development of enterprises in the long term [12], [14], [15].

Hypothesis H5: The social responsibility factor have a positive influence for the SD of SMEs in Vietnam.

\section{B. Data processing method}

The study applies convenience sampling method to survey collected feedback data of business managers, to assess the impact of management capacity on SD of SMEs in Vietnam.. A total of 350 votes were distributed and the number of valid votes for data processing was 316 votes.

Through Cronbach's Alpha coefficient, the research tests the reliability of the scales in the research model. Then, Exploratory Factor Analysis (EFA) was conducted to check the convergence and discriminant value of the variables in the research model.. Finally, the study uses multivariate regression methods to evaluate the impact of management capacity of enterprises compared to the following factors: Government supporting policy; Corporate social responsibility; 
Manufacturing technology and resources of enterprises for the SD of SMEs in Vietnam.

\section{RESULTS}

\section{A. Descriptive statistics}

From the results of primary data collection, the number of SMEs show that by geographical area participating in the survey are present in all three regions of the North, Central and South regions.

The data in Table II shown that, the results of the above survey of SMEs in Vietnam by industry and enterprise size. There were 316 valid questionnaires included in the data processing. In which, the number of SMEs in the field of trade and services accounts for $45.2 \%$; The number of enterprises in the agricultural, forestry and fishery sector accounts for $13.3 \%$.

TABLE I

STATISTICS OF SALARIES OF SURVEY ENTERPRISES BY GEOGRAPHIC

\begin{tabular}{|l|c|c|c|c|}
\hline \multicolumn{1}{|c|}{ Size } & Micro & Small & Medium & $\begin{array}{l}\text { Density by } \\
\text { region (\%) }\end{array}$ \\
\hline Geographical Area & 56 & 45 & 24 & 39,6 \\
\hline Central region region & 35 & 37 & 15 & 27,5 \\
\hline Southern region & 40 & 41 & 23 & 32,9 \\
\hline $\begin{array}{l}\text { Total number of } \\
\text { Enteprises }\end{array}$ & 131 & 123 & 62 & 100 \\
\hline
\end{tabular}

TABLE II

STATISTICS OF SURVEYED ENTERPRISES BY INDUSTRY AND SCALE

\begin{tabular}{|l|c|c|c|c|c|}
\hline $\begin{array}{c}\text { Scale } \\
\text { Business lines }\end{array}$ & $\begin{array}{l}\text { Super } \\
\text { small }\end{array}$ & $\begin{array}{l}\text { Smal } \\
\text { Butstics OF SURVEYED ENTERRISES BY INDUSTRY AND SCALE }\end{array}$ & $\begin{array}{l}\text { Mediu } \\
\mathrm{m}\end{array}$ & Total & $\begin{array}{c}\text { Proportion } \\
\text { by industry } \\
(\%)\end{array}$ \\
\hline $\begin{array}{c}\text { Agriculture- } \\
\text { forestry-fishery }\end{array}$ & 16 & 19 & 7 & 42 & 13,3 \\
\hline $\begin{array}{l}\text { Industry and } \\
\text { Contribution }\end{array}$ & 35 & 66 & 30 & 131 & 41,5 \\
\hline $\begin{array}{l}\text { Trade and } \\
\text { services }\end{array}$ & 40 & 72 & 31 & 143 & 45,2 \\
\hline $\begin{array}{l}\text { Total of } \\
\text { enterprises }\end{array}$ & 91 & 157 & 68 & 316 & 100 \\
\hline $\begin{array}{l}\text { Proportion of } \\
\text { scale (\%) }\end{array}$ & 28,8 & 49,7 & 21,5 & 100 & 100 \\
\hline
\end{tabular}

\section{B. Verify the reliability of the scale}

The results of Cronbach's Alpha (CA) reliability coefficient (after removing observed variables QL3 and RE2 due to their total correlation coefficients less than 0.4 ) showed that all coefficients CA of all groups of observed variables is greater than 0.6. Therefore, after testing Cronbach's alpha coefficient, the scales of the independent and dependent variables in the research model are eligible for EFA analysis.

\section{Exploratory factor analysis}

Based on the results of exploratory factor analysis (EFA), the model research have seven factors extracted from $30 \mathrm{ob}-$ served variables. Eigenvalues $=1,162>1$. From the above results, it can be confirmed that the number of factors extracted in the results of EFA analysis is appropriate. The total explanatory variance of the factor analysis was $68.211 \%>50 \%$.
The research variables with extracted variance $>50 \%$ were satisfactory and kept. At the same time, the observed variables must ensure the convergence value and distinguish between the groups of factors, the observed variables all have load system $>0.4$.

From the results of EFA analysis, the $\mathrm{KMO}$ value $=0.785$ $>0.6$. Bartlett's test value with hypothesis (H0) is "uncorrelated variables" with Sig value $=0.00<0.05$. The results of the EFA analysis for the group of dependent factors that are give the results: $\mathrm{KMO}$ coefficient $=0.768>0.5$ and significance level is $0.000<0.05$. From the above analysis results, it is shown that the results of factor analysis are consistent with the research data.

From the groups of factors extracted in the EFA analysis, the group of enterprise resource factors is diviided into two separate groups of factors, which are factors: financial resources (TC) and human resources (NL).

\section{Regression analysis}

After linear regression analysis, the value of $\mathrm{R}=0.726$ and adjusted R2 was 0.703 . This value shows that, the independent variables in the research model explain $70.3 \%$ of the variation of the dependent variable as "SD of SMEs in Vietnam". Through the results of ANOVA analysis, the F value $=61,225$ has statistical significance $\mathrm{Sig}=0.002<$ 0.05 . Thereby, it shows that the research model ensures reliability.

TABLE III

BETA COEFFICIENTS AFTER PERFORMING REGRESSION

\begin{tabular}{|c|c|c|c|c|c|}
\hline & $\begin{array}{c}\text { The coefficient is not } \\
\text { standardized }\end{array}$ & $\begin{array}{c}\text { Standardized } \\
\text { coefficient }\end{array}$ & Testing value \\
\cline { 2 - 4 } & B & $\begin{array}{c}\text { Standard } \\
\text { erros }\end{array}$ & Beta & $\begin{array}{c}\text { Level of } \\
\text { significance } \\
\text { Sig. }\end{array}$ \\
\hline Constant) & $-1,435$ & 0,265 & & $-4,251$ & 0,000 \\
\hline SX & 0,461 & 0,068 & 0,289 & 6,623 & 0,000 \\
\hline CS & 0,452 & 0,038 & 0,215 & 5,651 & 0,002 \\
\hline NL & 0,118 & 0,035 & 0,188 & 3,232 & 0,015 \\
\hline TC & 0,102 & 0,057 & 0,252 & 3,412 & 0,003 \\
\hline TN & 0,285 & 0,026 & 0,152 & 5,213 & 0,001 \\
\hline QL & 0,105 & 0,052 & 0,243 & 4,253 & 0,002 \\
\hline
\end{tabular}

Based on the data in Table III, it can be seen that the manufacturing technology factor (SX) has the most influence for the SD of SMEs in Vietnam, with the largest value $\beta=$ 0.289 . The corporate social responsibility (CS) has the lowest $(\beta=0.152)$. Sig value of all variables in the model research $<0.05$. Especially, the factor of management capacity has a greater influence than 3 factors in the research model $(\beta=0.243)$, included: Financial, Government policy and Corporate social responsibility. It can be explained here that, the management capacity of the managers in the organization has a clear and it has positive impact for the SD of SMEs in Vietnam. The role of management capacity clearly shown through the results of this study.

\section{E. Testing statistical hypotheses}

To determine the difference of types of enterprises in terms of factors affecting the management capacity of SMEs, the study uses Anova analysis method. If the Sig coefficient $>0.05$, then the hypothesis $\mathrm{H} 0$ is rejected, accept hypothesis $\mathrm{H} 0$ when $\mathrm{Sig}<0.05$. This explains that, there are 
differences in business types and industries in the influence of management capacity for the SD of SMEs in Vietnam.

The test results show that, the $\mathrm{H} 0$ hypothesis is rejected because testing the difference by type of enterprise with value $\mathrm{Sig}=0.012$; The difference test by business line has the value $\mathrm{Sig}=0.001$.

It can be seen that, the role of management capacity factor has been clearly shown through the results of this study. Management capacity has a greater influence than the factors of enterprises's financial, corporate social responsibility and government policy in the SMEs sector in Vietnam. Before businesses receive good support from the government's policies or well implement social responsibility for the community, the issue of corporate management so that efficiency is always a top priority.

\section{Conclusion and Future Research Directions}

The enterprise have a team of managers from senior to grassroots level with good ability, it will help their business to orient well the organization's operational goals. In addition, it will help to effectively coordinate and promote the productivity of all resources in the organization, to help the organization adapt to the negative impacts of the governance environment .

How to improve the production technology process and where is start to improve this problem? If managers have good thinking skills, staff skills and technical skills, they will greatly contribute to helping businesses orient their strategies to operate effectively.

Through this study, the authors propose some solutions to improve management capacity for the SD of SMEs in Vietnam. Firsly, to improve the quality of management, the quality of human resources in the enterprises, detail as: Actively associate and cooperate with educational and training institutions, especially universities related to the field of manufacturing to improve professional qualifications and management skills for business managers. With that to have a HR vision such as effectively attracting and retaining a skilled workforce. Secondly, expanding linkages between SMEs associations and local businesses. Through this linkage activity, it will help managers access and timely update changing trends in production and business, relevant legal regulations to promptly orient business activities. Effective. Thirdly, to promote training activities in outside of the enterprise. It is necessary to actively support junior managers (direct labor managers) and middle managers need to participate in training courses in outside of the enterprise. Training activities on responding to occupational accidents in production to be able to approach and learn, improve skills to promptly respond to incidents that may occur in the production process. The study has clarified the role of the management capacity factor for the SD of SMEs in Vietnam.

However, the study still has certain limitations and will be to improve for the future research. Firstly, the sample size is not large, the number of enterprises participating in the survey is still small. For the future research directions, we will be expand the research scope, expand the assessment object of enterprises in other fields for activity. Secondly, the results of analysis are mainly used of the regression analysis model, the research model have not to be consider intermediate and regulatory variables in the research model. For the future research directions, we will be expand the scope of the study and to consider additional intermediate variables to clarify the influencing factors in addition to those included in the current research model.

\section{REFERENCES}

[1] General Statistics Office of Vietnam, 2019

[2] Trinh Duc Chieu, 2010. The impact factor influence to growth of small and medium enterprises in Viet Nam, Government Economics Research.

[3] Phung The Dong, 2019, Supporting Vietnam's small and mediumsized enterprises in their current development. Finance Journal, No.11.

[4] Cant, M. C., \& Wiid, J.A. (2013). Establishing the Challenges Affecting South African SMEs. International Business \& Economics Research Journal, 12(6), 707-716).

[5] Hien, N . (2019). Study Factors Affecting Management Capacity and the Business Effectiveness: A Case of Small and Medium Enterprises in Vietnam. Academy of Entrepreneurship Journal.

[6] Chen, J. (2006). Development of Chinese small and medium-sized enterprises. Journal of Small Business and Enterprise Development, 13(2), 140-147.).

[7] Chuthamas, C. (2011). Factors Affecting Business Success of Small \& Medium Enterprises (SMEs) in Thailand. Asian Social Science, 7(5), 180-190

[8] Le Ngoc Nuong, 2018. Factors affecting the development of small and medium industrial enterprises in Thai Nguyen-Viet Nam, Economic and Business Management University.

[9] Luminita, P. (2020). The Role of Managerial Skills in the SD of SMEs in Mehedinti Country, Romania. Sustainability Journal, 2020, 12(3).

[10] Peng.T, Zhao.C, 2019. Research on the Survival and SD of Small and Medium Enterprises in China under the Background of Low-Carbon Economy, Open Access Journal, vol. 11(5), pages 1-17.

[11] Ministry of SD targets of enterprises, 2017-2019. Viet Nam Chamber of Commerce and Industry (VCCI).

[12] Phan Van Dan, 2012. Building a scale for enterprise sustainability, Scientific Journal, Can Tho University.

[13] Ibrahim. U, 2008. An analysis of strategic factors affecting the performance of small and medium industries in Borno State of Nigeria. St Clements University, Nigeria.

[14] Hung, D\&Nguyen,H.2020. Corporate Social Responsibility for SD of Small and Medium Enterprises in Vietnam. Journal of Business and Economic Development, 2020, 5(3): 157-163

[15] Okpara, J.O., \& Kabongo, J.D. (2009). An empirical evaluation of barriers hindering the growth of SMEs in a Developing Economy. African Journal of Business and Economic Research, 4(1), 7-21.). 